\title{
The farmers' knowledge of the techniques of the sustainable agriculture in Assuit governorate, Egypt
}

\author{
Abo Elenein M.A.* \\ Department of Agricultural Extension and Rural Sociology, Faculty of Agriculture, Al-Azhar University, Assuit, Egypt
}

\begin{abstract}
This research aimed to identify the level of knowledge of the respondents farmers concerning with sustainable agriculture techniques in Assiut governorate, the obstacles facing them while using sustainable agriculture techniques, and their proposals to overcome these obstacles and to know the relationship between the level of knowledge farmers concerning with sustainable agriculture techniques and their independent studied variables. This research has been carried out in Assiut governorate; two districts were randomly selected from the governorate. These are Assiut and Aboitig A village was randomly selected from each district, respectively, Mankabad and Masoudi. The sample was randomly selected from the villages of the study with $10 \%$ of the total number of farmers in each village. The sample was as follows: 124 respondent farmers in the village of Mankabad in Assiut district. The total number of farmers in this village is 1242 farmers and 85 respondents in the village of Masaoudi in Aboitig district. The total number of village farmers is 850 farmers, and the data were collected by personal interview using a questionnaire prepared specifically for this purpose during the month of July and August 2017. Data were analyzed and shown using illustrating tables, frequencies, analysis, that was done through using a percentages, and chi-square test package of statistical programs of social sciences (SPSS).
\end{abstract}

The results indicated that:

1. Knowledge level of $71.29 \%$ respondents farmers were average or low for sustainable farming techniques.

2. The most important obstacles facing farmers when using sustainable agriculture techniques are: lack of sources of selling biological fertilizers, high costs of importing natural resistants, and some techniques such as modern irrigation methods, and the absence of incentives by the agricultural extension organization.

3. The most important proposals of farmers to overcome the obstacles facing them when using sustainable agriculture techniques are: providing sources for selling of bio-fertilizers in agricultural societies, finding a specialist to multiply the natural resistants, and providing the necessary loans to farmers to buy modern irrigation supplies.

4. There is significant relationship between the level of knowledge of the farmers concerning with sustainable agriculture techniques, and each of their following independent variables: age, educational level, agricultural holding capacity, and sources of information.

Keywords: farmer's knowledge, sustainable agriculture, techniques of the sustainable agriculture, Assiut.

\footnotetext{
* Corresponding author: Abo Elenein M.A.
}

E-mail address: mostafa28968@gmail.com 


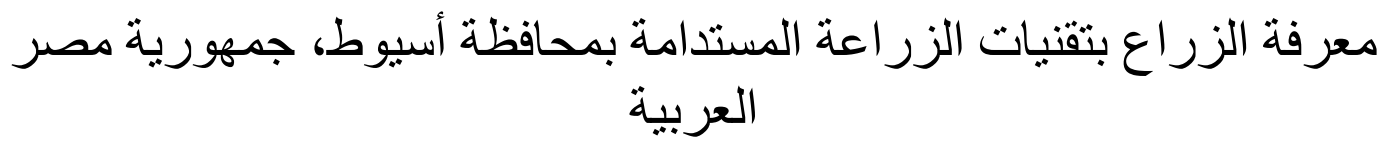

\author{
مصطفي عبد الحميد أبو العنين \\ قسم الإرشاد الزراعى والمجتمع الريفى، كلية الزراعة، جامعة الأزهر بأسيوط، جمهورية مصر العربية
}

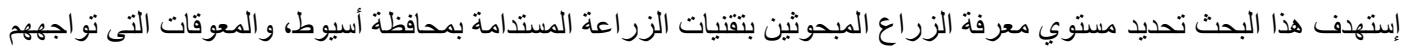

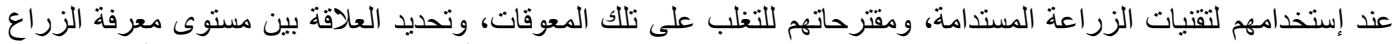

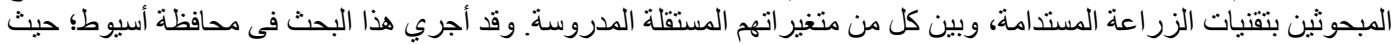

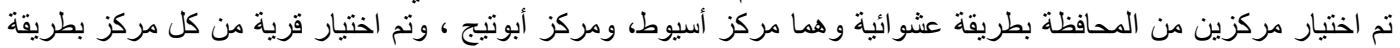

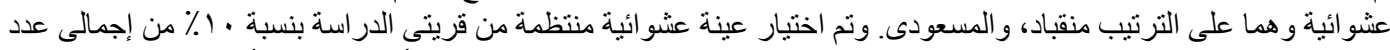

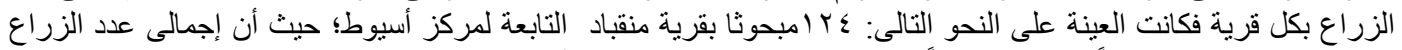

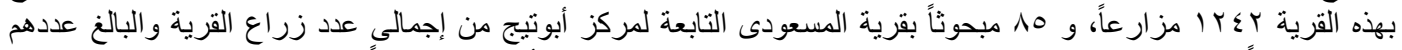

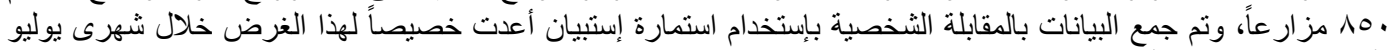

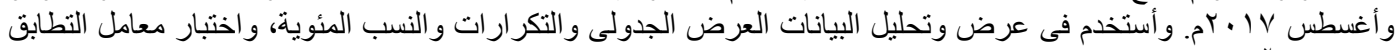

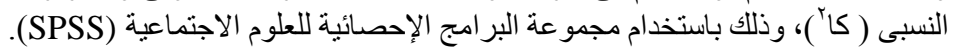

$$
\text { وكانت أهم النتائج ما يلى: }
$$

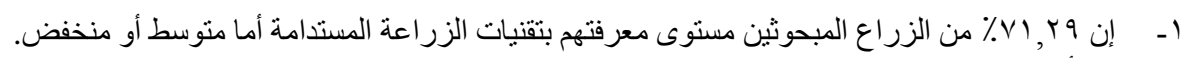

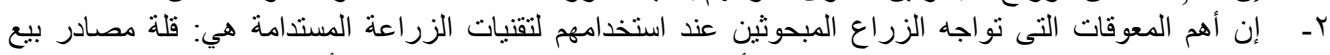

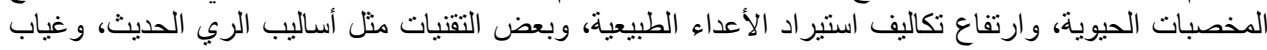

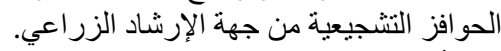

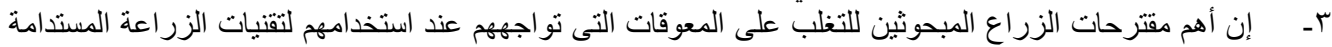

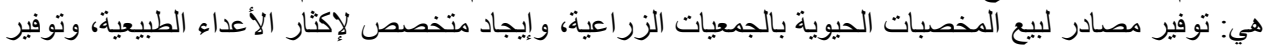

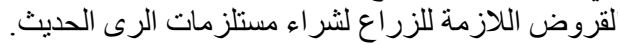

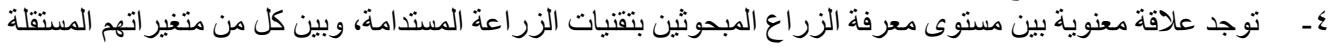

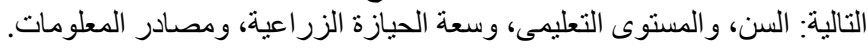
كلمات دالة: معرفة الزراع ، الزر اعة المستدامة ، تقنيات الزرعة ، أسيوط. 
إذ أنه يتعامل مع البيئة الريفية بمفهومها الثامل، والتى منها

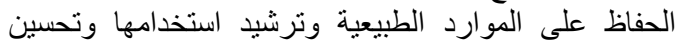

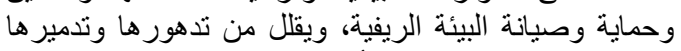

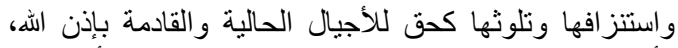
وأصبح من الضروري على جهاز الإرشاد الزر اعلى أنى أن يطور

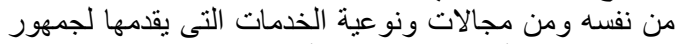

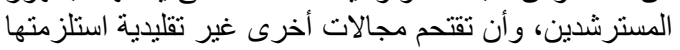

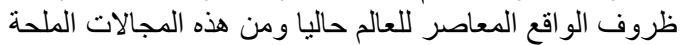

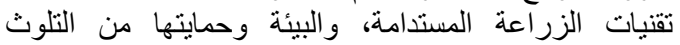
وصيانتها ومحاولة الحفاظ عليها لاستدامتها لخدمة الإنة الأجيال

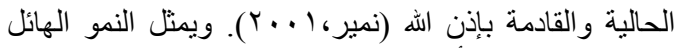

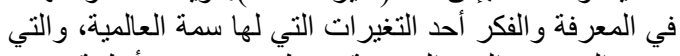

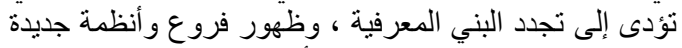

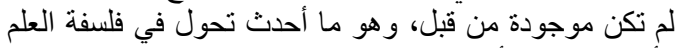

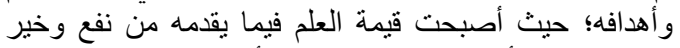

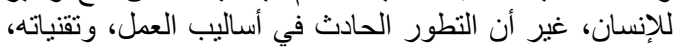

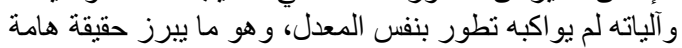

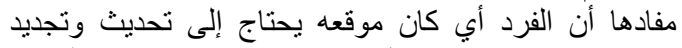

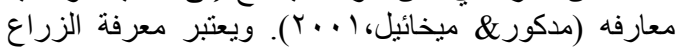

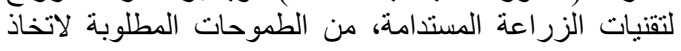

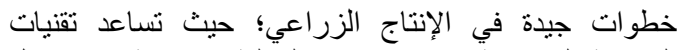

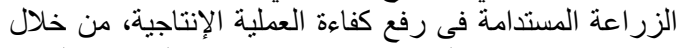

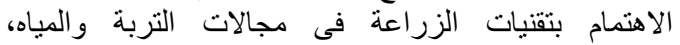

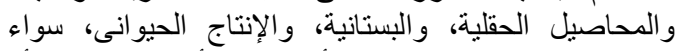

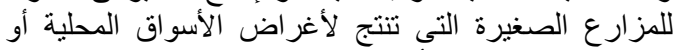

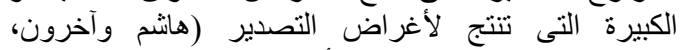
بول...V

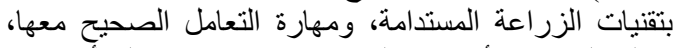

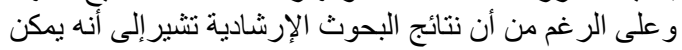

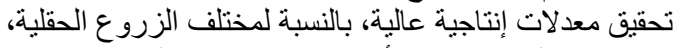

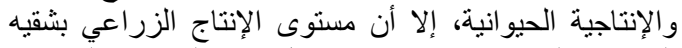

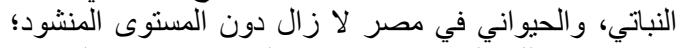

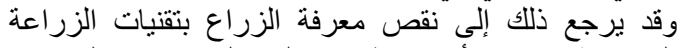

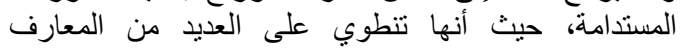

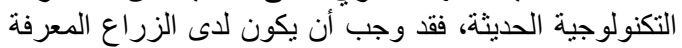

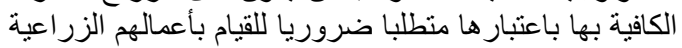

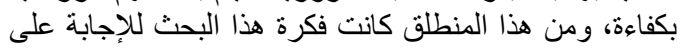

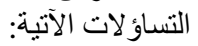

ا - ما هو مستوي معرفة الزراع المبحوثين بتقنيات

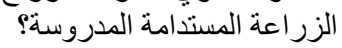

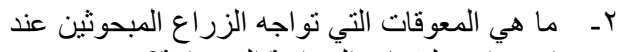

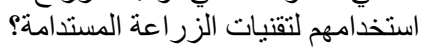

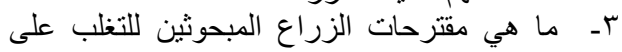

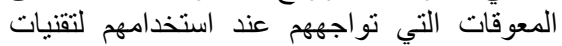

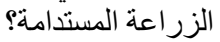

ما هي العلاقة بين بعض المتغخير ات المستقلة للزراع المبحوثين

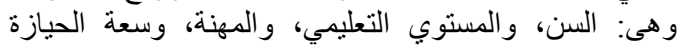

\section{المقدمة والمشكلة البحثية}

تعد الزر اعة أساس كل تطور حضارى ورخاء و أمن لحياة

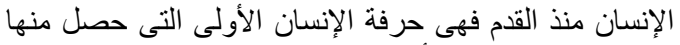

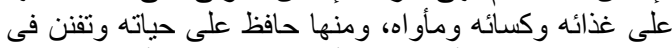

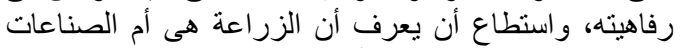

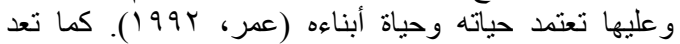

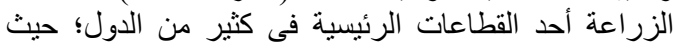

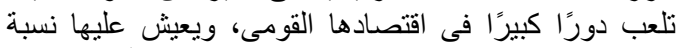

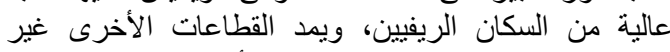

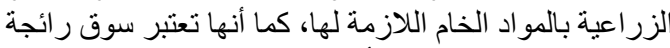
لمنتجات تلك القطاعات الأخرى (عبد المقصودة،

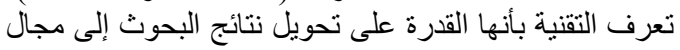

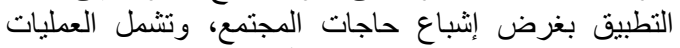

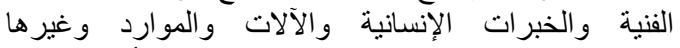

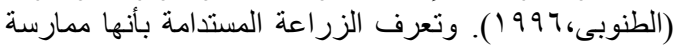

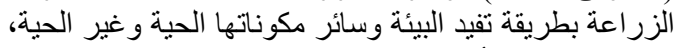

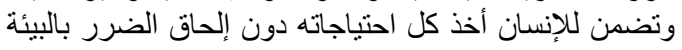

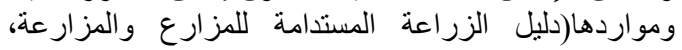

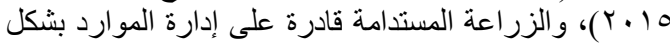

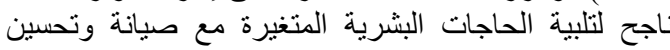

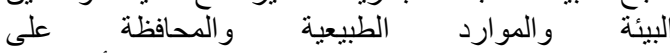

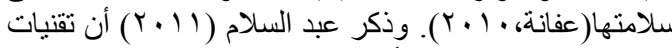
الزراعة المستدامة يجب أن تتصف بالخصائص أنس التالية: إنتاج غذاء كافى وذو جوده عالية، وحماية البيئة، وتحافظة على الئى

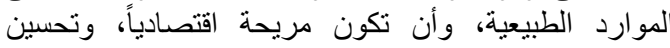

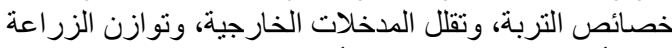

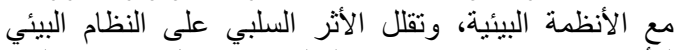

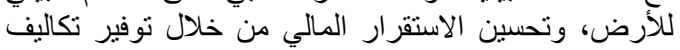

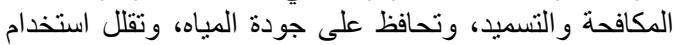

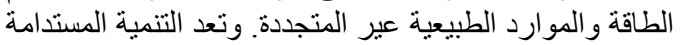

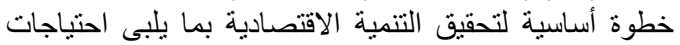

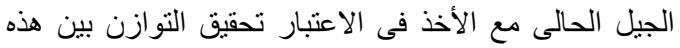
الاحتياجات ومتطلبات المستقبل بشكل يضمن الإن عدم تدهور البيئة

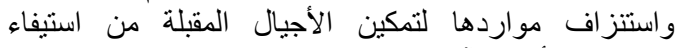

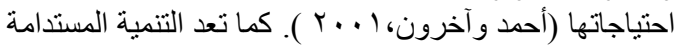

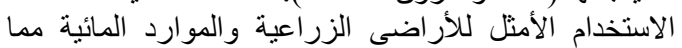

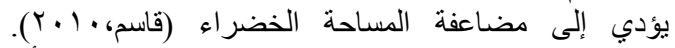

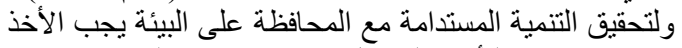

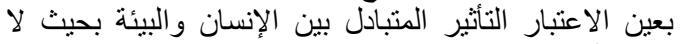

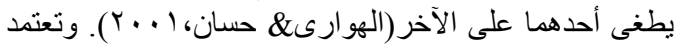

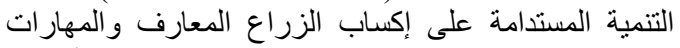

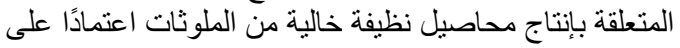

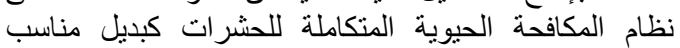

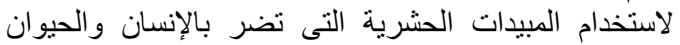

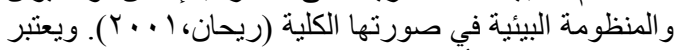

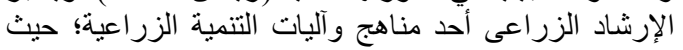

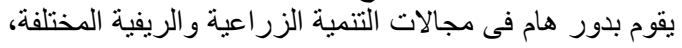


الفرض البحثى السابق ذكره نم صياغة الفروض الإحصائية

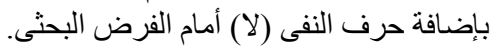

\section{الطريقة البحثية}

أجري هذا البحث فى محافظة أسيوط؛ حيث تم اختيار مركزين

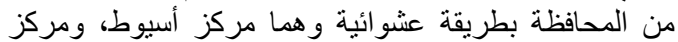

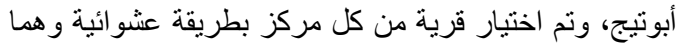

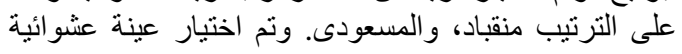

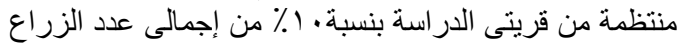

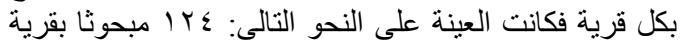

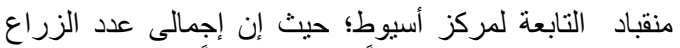

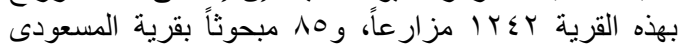

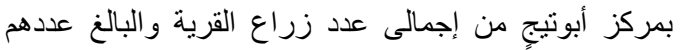

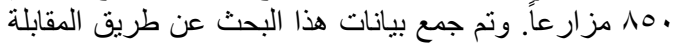

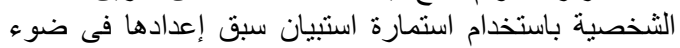

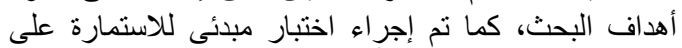

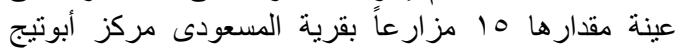

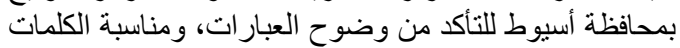

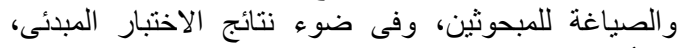

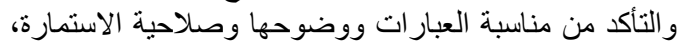

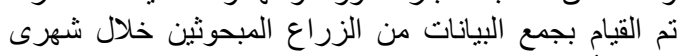

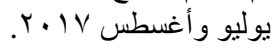

\section{المعالجة الكمية للبيانات}

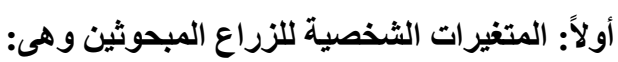

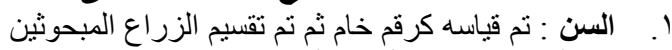

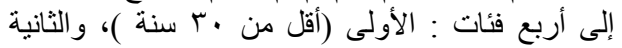

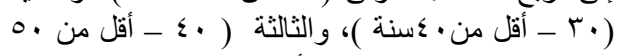
سنة )، و الر ابعة ( • (مسنة فأكثر ).

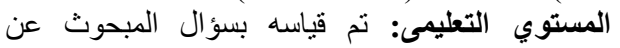

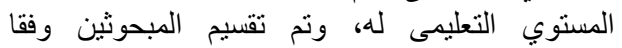

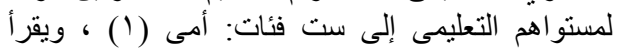

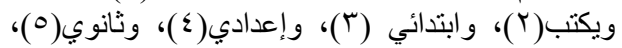

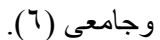

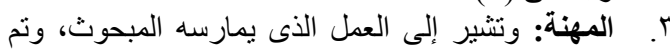

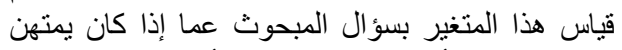

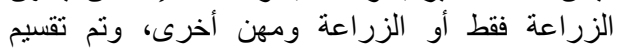

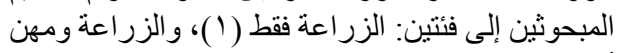

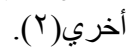

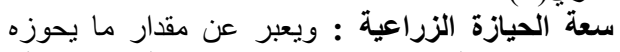

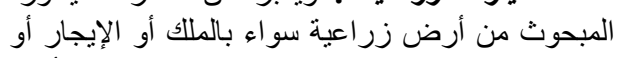

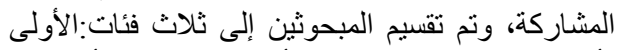

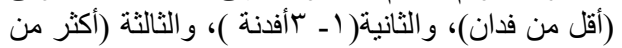

ثلاثة أفننة).

○. مصادر المطلومات: يثير هذا المتغير إلى مدى مواظبة
الزراعية، ومصادر المعلومات، ومحل الإقامة، وبين مستوي معرفتهم بتقنيات الزر اعة المستدامة؟

أهداف البحث

بناءاً على عرض مقدمة البحث ومشكلته تحددت أهداف

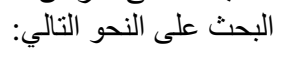

'. . تحديد مستوى معرفة الزراع المبحوثين بتقنيات الزراعة

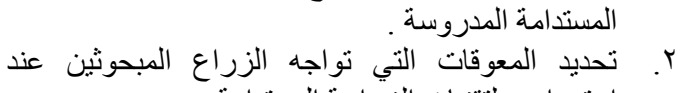

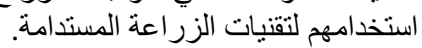

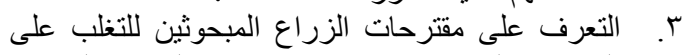

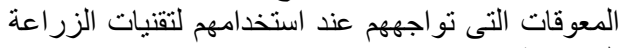

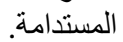

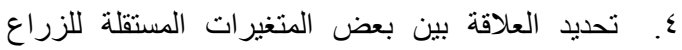

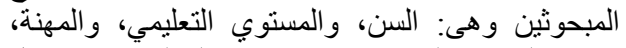

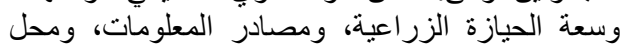

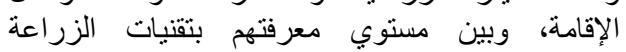

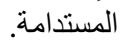

\section{أهمية البحث}

تساعد نتائج هذا البحث في التعرف على مستوى معرفة

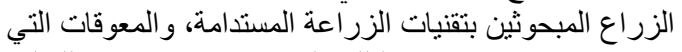

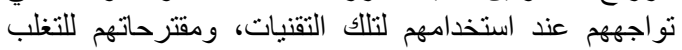

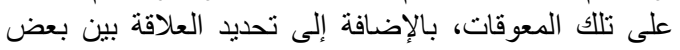

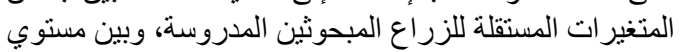

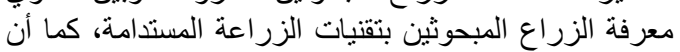

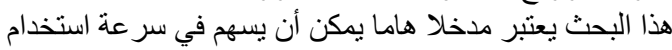

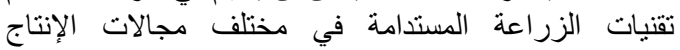

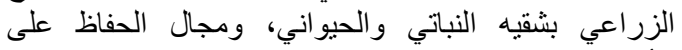

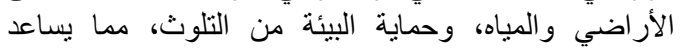

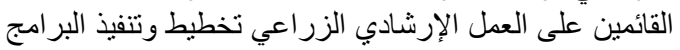

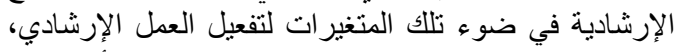

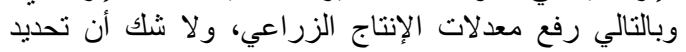

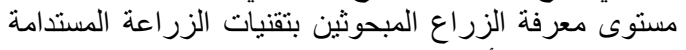

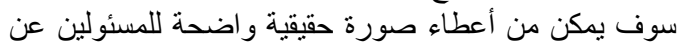

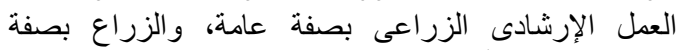
خاصة، ومعالجة أوجه القصور في المعرفة.

لتحقيق هدف البحث الرابع تم صياغة الفرض البحثى التالى:

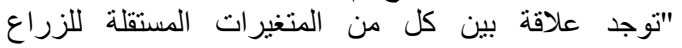

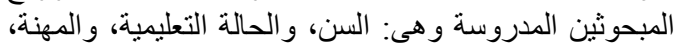

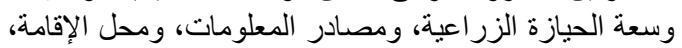
وبين مستوي معرفتهم بتقنيات الزراعة الزعة المستدامة". و ولاختبار الإنة 
تم حساب التكرارات والنسب المئوية لكل معوق ثم رتبت

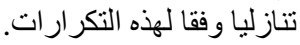

رابعاً: فيما يتعلق بمقترحات الزراع المبحوثين للتفلب

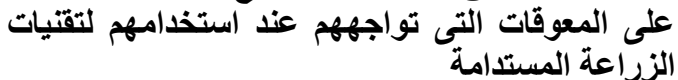

تم حساب التكرارات والنسب المئوية لكل مقترح ثم رتبت التباء تنازليا وفقا لهذه التكرارات.

الأدوات المستخدمة فى التحليل الإحصائى

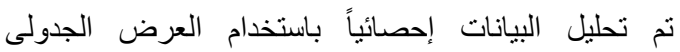

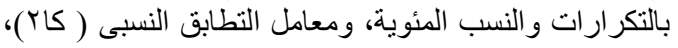
وذلك باستخدام مجمو عة البر امج الإحصائية للعلوم الاجتماعية النية

.SPSS

\section{التتائج ومناقشتها}

أولاً: المتغيرات الثخصية للزراع المبحوثين

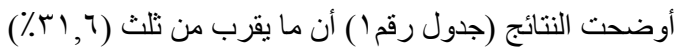

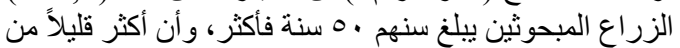

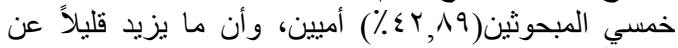

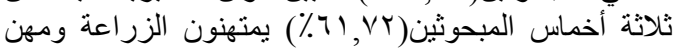

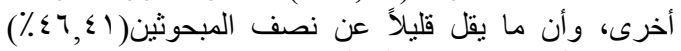

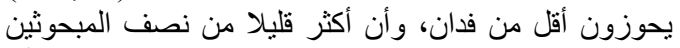
(\%), TV)

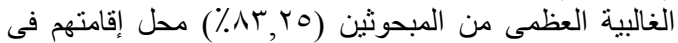

ثانياً: مستوي معرفة الزراع المبحوثين بتقنيات الزراعة

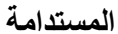

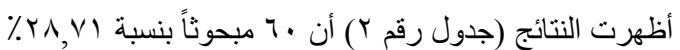

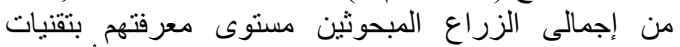

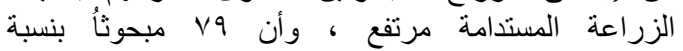

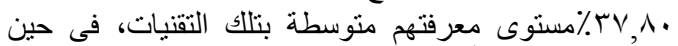

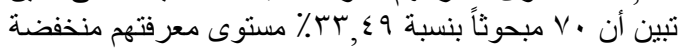

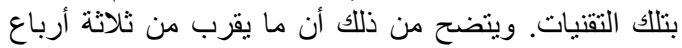

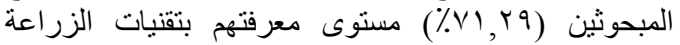

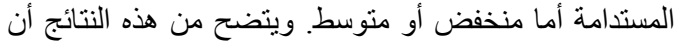

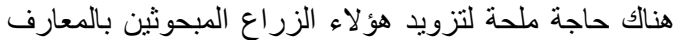

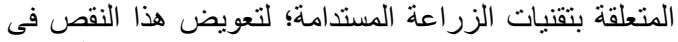

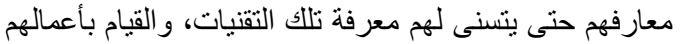
بكفاءة، وزيادة الإنتاج الزر اعي.

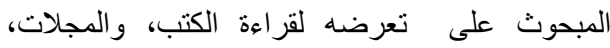

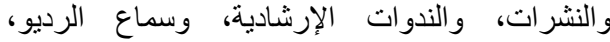

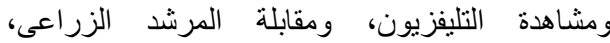

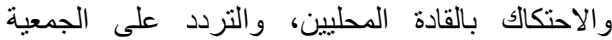

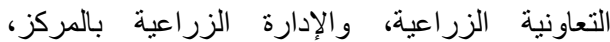

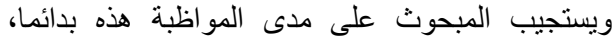

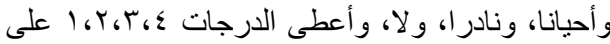

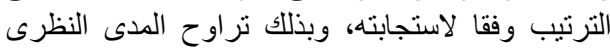

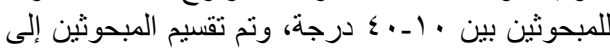

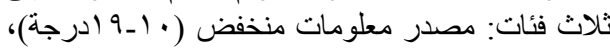

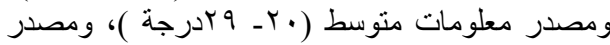
معلومات مرتفع ( • بردرجة فأكثر ).

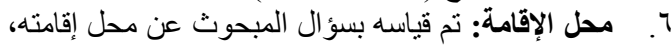
وتم تقسيم المبحوثين وفيه بقا لمحل الإقامة إلى فئى فئتين:

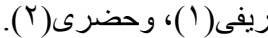

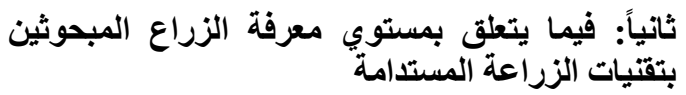

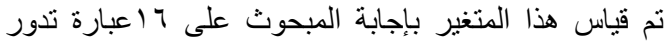

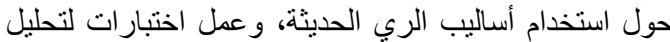

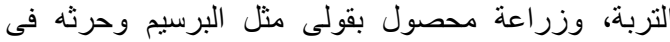

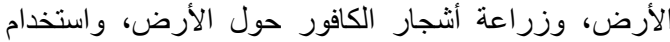

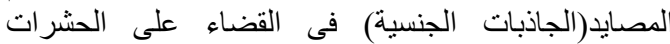

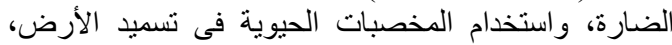

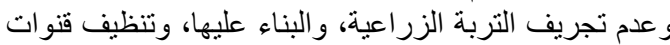

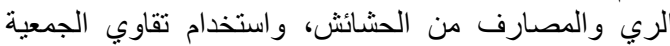

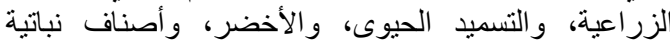

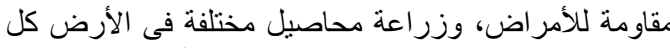

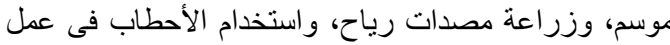

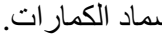

وتتضمن إجابة المبحوث على هذه العبارات السابقة الاختيار

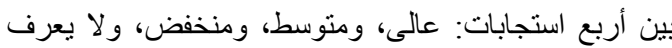

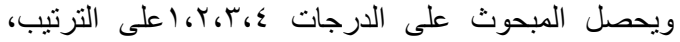

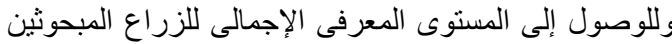

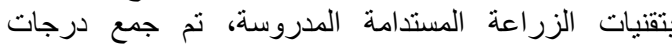

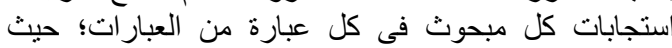

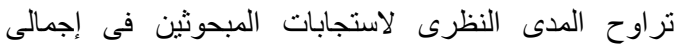

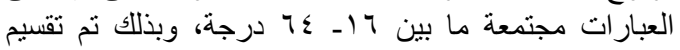

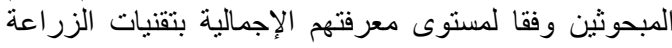

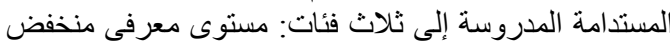

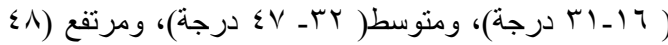

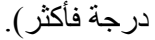

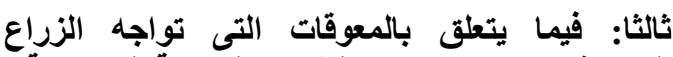
المبحوثين عند استخدامهم لتقنيات الزراعة التى المستدامة المراع 


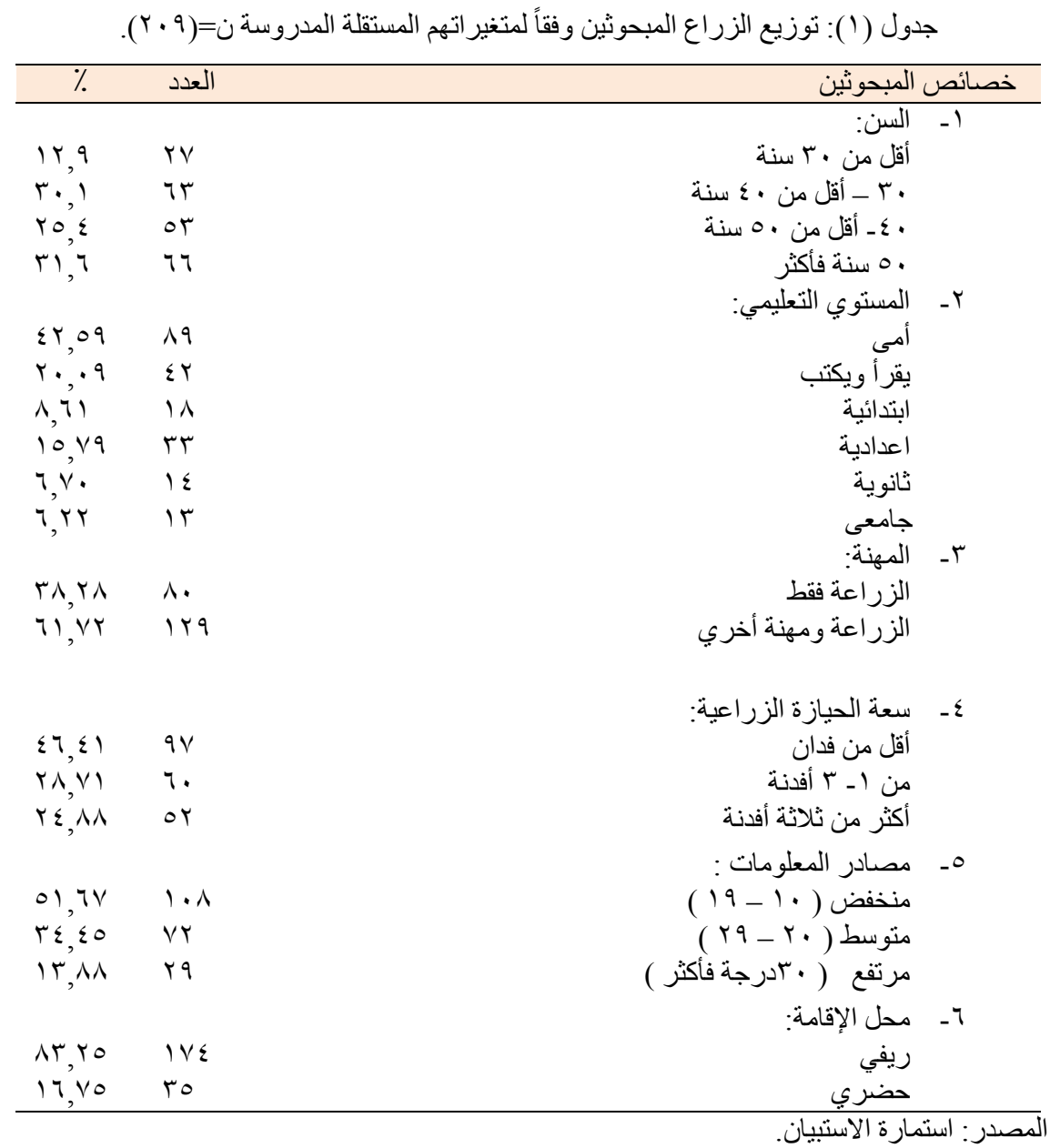

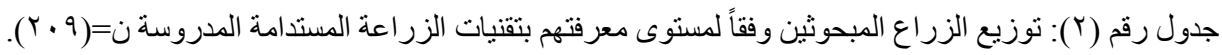

\begin{tabular}{|c|c|c|}
\hline$\%$ & العدد & المستوى المعرفى \\
\hline r^,, $\mathbf{l}$ & 7. & مرتفع ( \\
\hline$r v, \Lambda$. & $\vee q$ & متوسط ( Tr _ \& ) \\
\hline$r r, \leqslant q$ & $V \cdot$ & منخفض ( 17 - ו" ) \\
\hline $1 \ldots$ & $r \cdot q$ & المجموع \\
\hline
\end{tabular}

المصدر : استمارة الاستبيان.

كانت مرتبة تنازليا على النحو التالي: قلة مصادر بيع

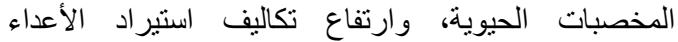

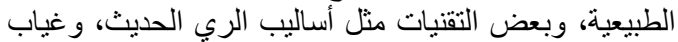

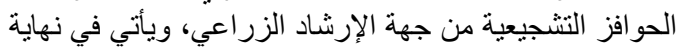

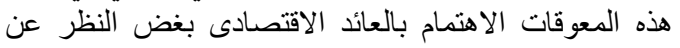

ثالثا:المعوقات التى تواجه الزراع المبحوثين عند

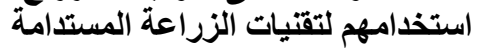

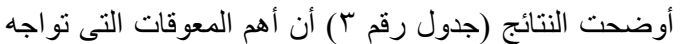

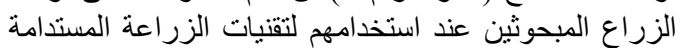


استخدامهم لتقنيات الزر اعة المستدامة كانت مرتبة تنازليا على التى

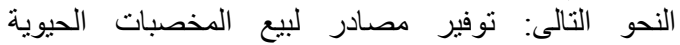

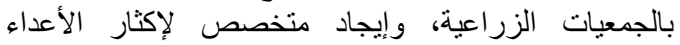

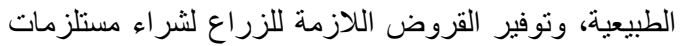

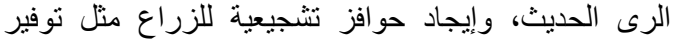

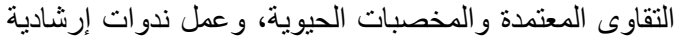

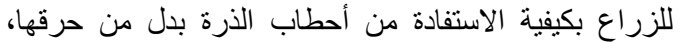

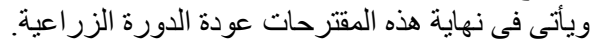

المحافظة على الأرض الزر اعية.

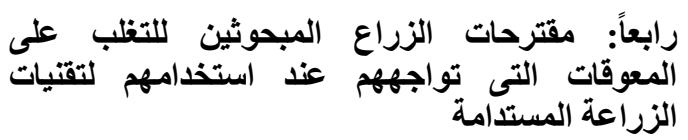

أظهرت النتائج (جدول رقم ؟) أن أهم المقترحات التى ذكرها

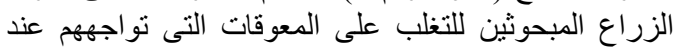

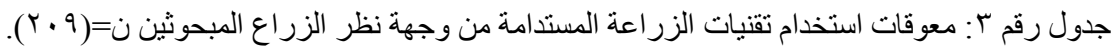

\begin{tabular}{|c|c|c|c|}
\hline$\%$ & عدد & المعوقات & م \\
\hline $9 \cdot, 9$ & 19. & قلة مصادر بيع المخصبات الحيوية. & 1 \\
\hline$\Lambda \leqslant, V$ & IVV & ارتفاع تكاليف استتير اد الأعداء الطبيعية. & r \\
\hline N & $1 V \varepsilon$ & ارتفاع تكاليف بعض التقنيات مثل أساليب الرى الحديث. & r \\
\hline VY,, & 104 & غياب الحو افز التشجيعية من جهة الإرشاد الزراعى. & $\varepsilon$ \\
\hline $7 \vee, 9$ & $1 \leq r$ & التخلص من أحطاب الذرة بالحرق. & 0 \\
\hline $09, \Gamma$ & IY & قصور المعلومات الإرشادية بشأن تجهيز و استخدام سماد الكمبوست. & 7 \\
\hline$\varepsilon 9, \wedge$ & $1 \cdot \varepsilon$ & ارتفاع تكاليف خدمة الأرض الزر اعية. & $\mathrm{v}$ \\
\hline$\leq 0$, & $9 \leq$ & الاهتمام بالعائد الاقتصادى بغض النظر عن المحافظة على الأرض الزر اعية. & $\wedge$ \\
\hline
\end{tabular}

جدول رقم ؛ : مقترحات الزراع المبحوثين للتغلب على معوقات استخدام تقنيات الزر اعة المستدامة ن=(9 • (Y).

\begin{tabular}{|c|c|c|c|}
\hline$\%$ & 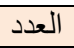 & 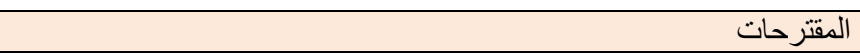 & r \\
\hline$\wedge \wedge$, & $1 \wedge \varepsilon$ & توفير مصنادر لبيع المخصبات الحيوية بالجمعيات الزراعية. & 1 \\
\hline Ar & IVT & إيجاد متخصص لإكثار الأعداء الطبيعية. & r \\
\hline$\vee 1, \wedge$ & 10. & توفير القروض اللازمة للزراع لشر اء مستلزمات الرى الحديث. & r \\
\hline T & ITh & إيجاد حو افز تشجيعية للزر اع مثل توفير التقاوى المعتمدة والمخصبات الحيوية. & $\varepsilon$ \\
\hline$T, r$ & $1 T \cdot$ & عمل ندوات إرشادية للزر اع بكيفية الاستفادة من أحطاب الذرة بدل من حرقها. & 0 \\
\hline $09, \wedge$ & 1 ro & تعليم الزراع كيفية تجهيز واستخدام سماد الكمبوست بطريقة الإيضاح العملى. & 7 \\
\hline$\Delta \wedge, \varepsilon$ & Mt & توفير المعدات اللازمة لإعداد الأرض للزر اعة عن طريق الجمعيات الزر اعية. & $\mathrm{V}$ \\
\hline 07,9 & 119 & توعية الزر اع بأهمية الزر اعة المستدامة وفو ائدها. & $\wedge$ \\
\hline 00,0 & 117 & توعية الزراع بالطرق المناسبة لتسويق المحاصيل الزر اعية. & 9 \\
\hline or, 7 & $11 \cdot$ & تفعيل دور الإرشاد الزر اعى فى حل مشكلات الزراع. & 1 . \\
\hline $0 \cdot, r$ & 1.0 & عودة الدورة الزر اعية. & 11 \\
\hline
\end{tabular}

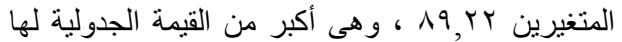
عند درجات حرية 7. وجود علاقة معنوية عند مستوى الُ, •بين المستوى

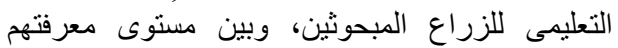

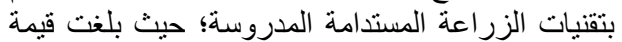

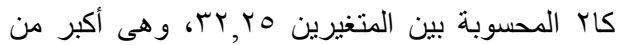

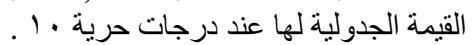

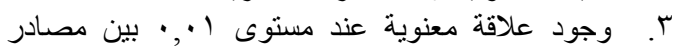

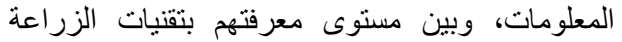

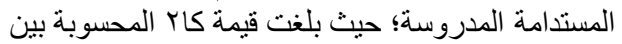

خامسا: العلاقة بين كل من المتغيرات المستقلة للزراع

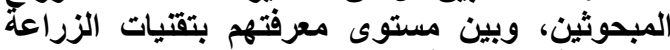
المستدامة المدرينة وبنة

أظهرت نتائج دراسة العلاقة بين كل من المتغيرات

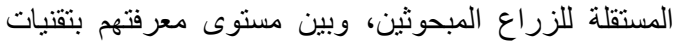

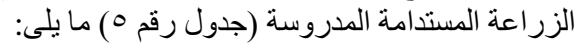

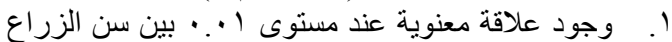

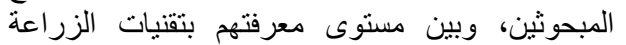
المستدامة المدروسة؛ حيث بلغت قيمة كاب المحسوبة بين 


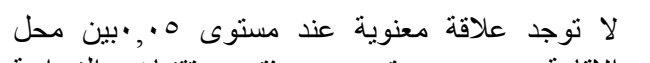

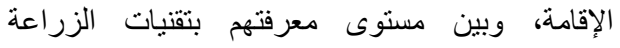

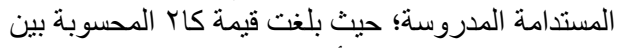

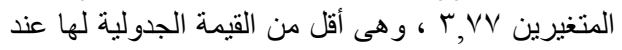

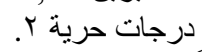

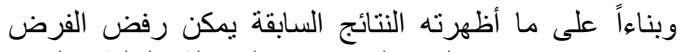

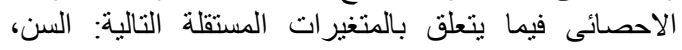

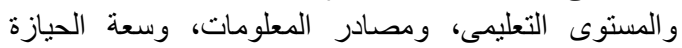

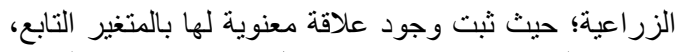

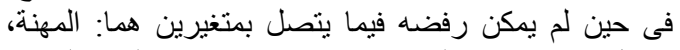

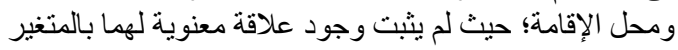
التابع.

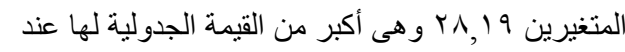

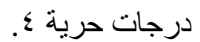

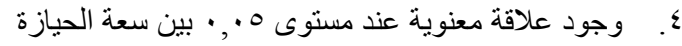

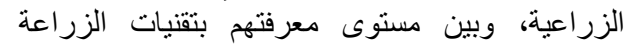

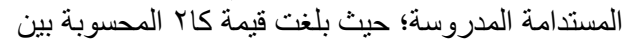

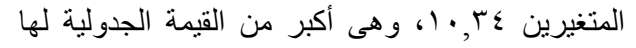

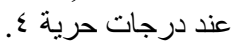
๑. لا توجد علاقة معنوية عند مستوى 0., •بين المهنة،

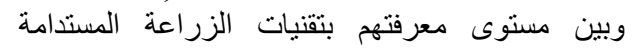

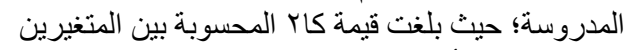

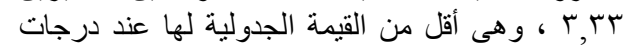

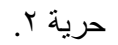

جدول رقم ه: قيم مربع كاى المحسوبة للعلاقة بين المتغير ات المستقلة للمبحوثين، وبين مستوى معرفتهم بالمتغير التابع المدروس.

\begin{tabular}{|c|c|}
\hline المستوى المعرفي بتقنيات الزر اعة المستدام قيم كا & المتغير ات \\
\hline${ }^{* *} \wedge 9, Y Y$ & السن \\
\hline 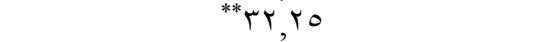 & المستوى التعليمى \\
\hline سץ, & المهنة \\
\hline$* 1 \cdot, r \leq$ & سعة الحيازة الزر اعية \\
\hline ** Y^,19 & مصادر المعلومات \\
\hline r,ve & محل الإقامة \\
\hline
\end{tabular}

القطاع الزر اعى، الطبعة الأولى، منشورات جامعة عمر المختار، البيضاء، ليبيا.

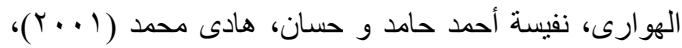

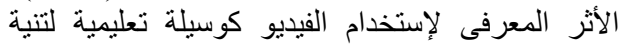

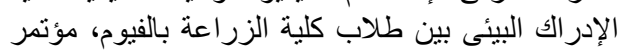

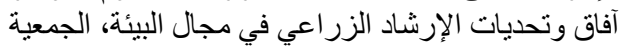

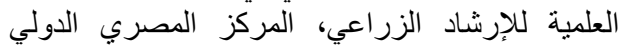

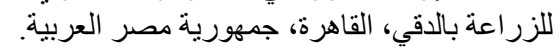

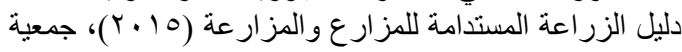

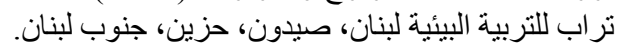

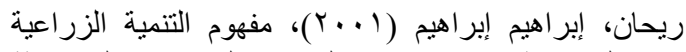

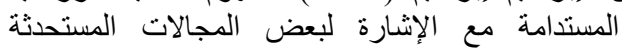

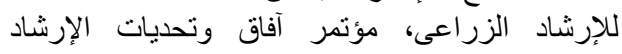

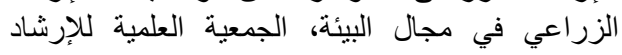

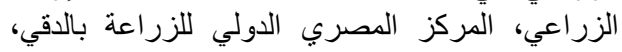

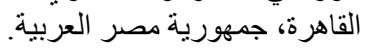

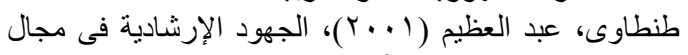

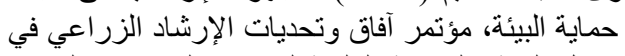

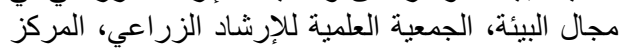

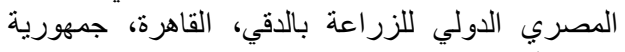

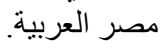

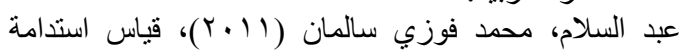

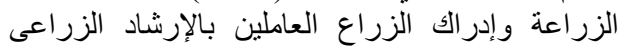

بناءً على ما توصل إليه البحث من نتائج، يوصى بما يلى:

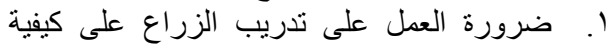

التعامل الصحيح مع تقنيات الزر اعة المعلى المستدامة.

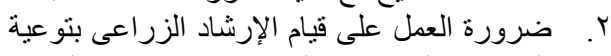

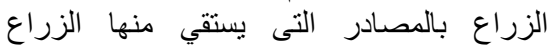

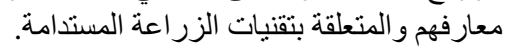

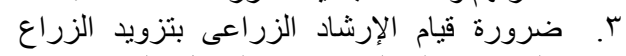

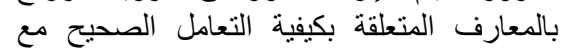
تقنيات الزر اعة المستدامة.

قائمة المراجع

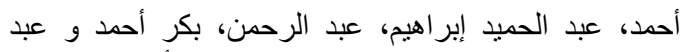

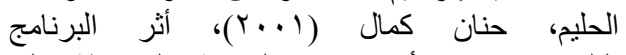

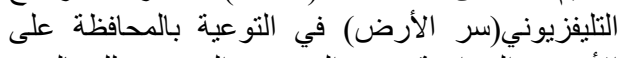

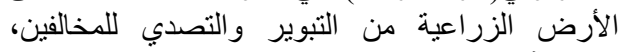

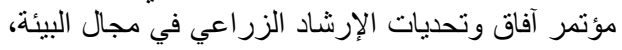

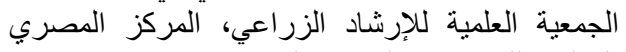

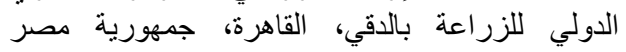
العربية. الطنوبى، محمد عمر (1997))، تدريب القوى العاملة فى 


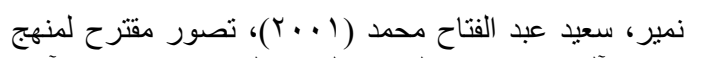

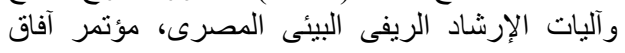
وتحديات الإرشاد الزراعى في الزئى مجال البيئة، الجمعية الزئية

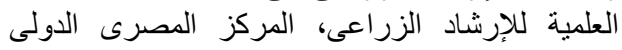

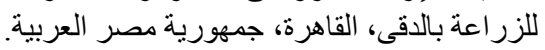

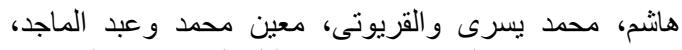

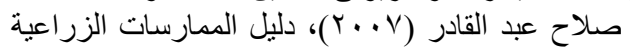

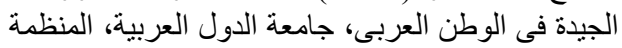
العربية للتنمية الزر اعبة، الخرطوم جامعة متاح على: .http://www.aoad.org/publications/GuideAgpract.pdf
لتقنياتها بمحافظة أسيوط، رسالة دكتور اه، كلية الزر اعة،

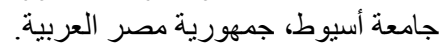

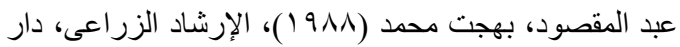

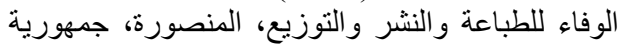

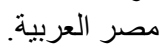

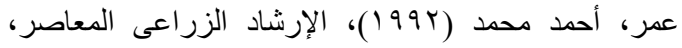

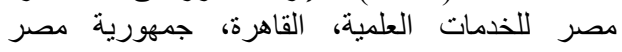
العربية.

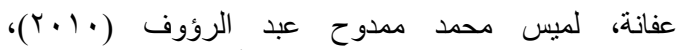

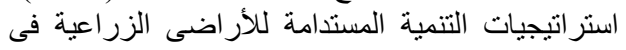

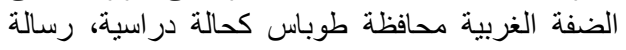
ماجستير، كلية الدراسات العليا، جامعة النجاح الوطنية، درالة نابلس، فلسطين.

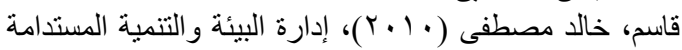

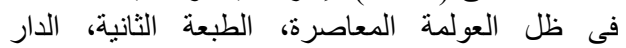
الجامعية، الأسكندرية، جمهورية مصر العرة العربية.

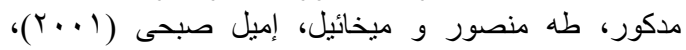

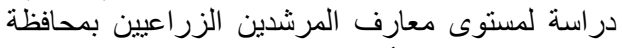

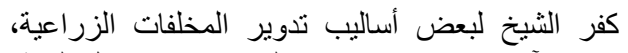

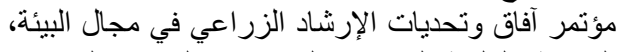

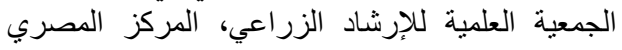

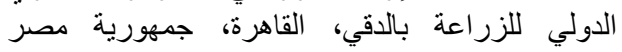

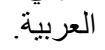

